Correction

\title{
Correction: Suwannapong, C. et al. Congestion Control in CoAP Observe Group Communication. Sensors 2019, 19, 3433
}

\section{Chanwit Suwannapong (D) and Chatchai Khunboa* $\mathbb{D}$}

Department of Computer Engineering, Faculty of Engineering, Khon Kaen University, 40002 Khon Kaen, Thailand; chanwit.s@kkumail.com

* Correspondence: chatchai@kku.ac.th

Received: 4 September 2019; Accepted: 6 September 2019; Published: 11 October 2019

The authors wish to make the following corrections to this paper [1]:

We have found two inadvertent errors in our paper published in this Sensors [1]:

1. In Section 3. of this paper [1], the sentence "Moreover, in each retransmission, the FPB (i.e., Fibonacci fib $n, n=\{1,2,3,5\})$ was multiplied by the $R T O_{\text {previous }}$ to determine the new RTO timer for the next retransmission." This sentence should be modified to state: "Moreover, in each retransmission, the FPB (i.e., Fibonacci fib $n, n=\{1,2,3,5\}$ ) was multiplied by the $R T O_{\text {init }}$ to determine the new RTO timer for the next retransmission."

2. In Section 3. of this paper [1], the following Algorithm 1 should be replaced with the Algorithm shown below it.

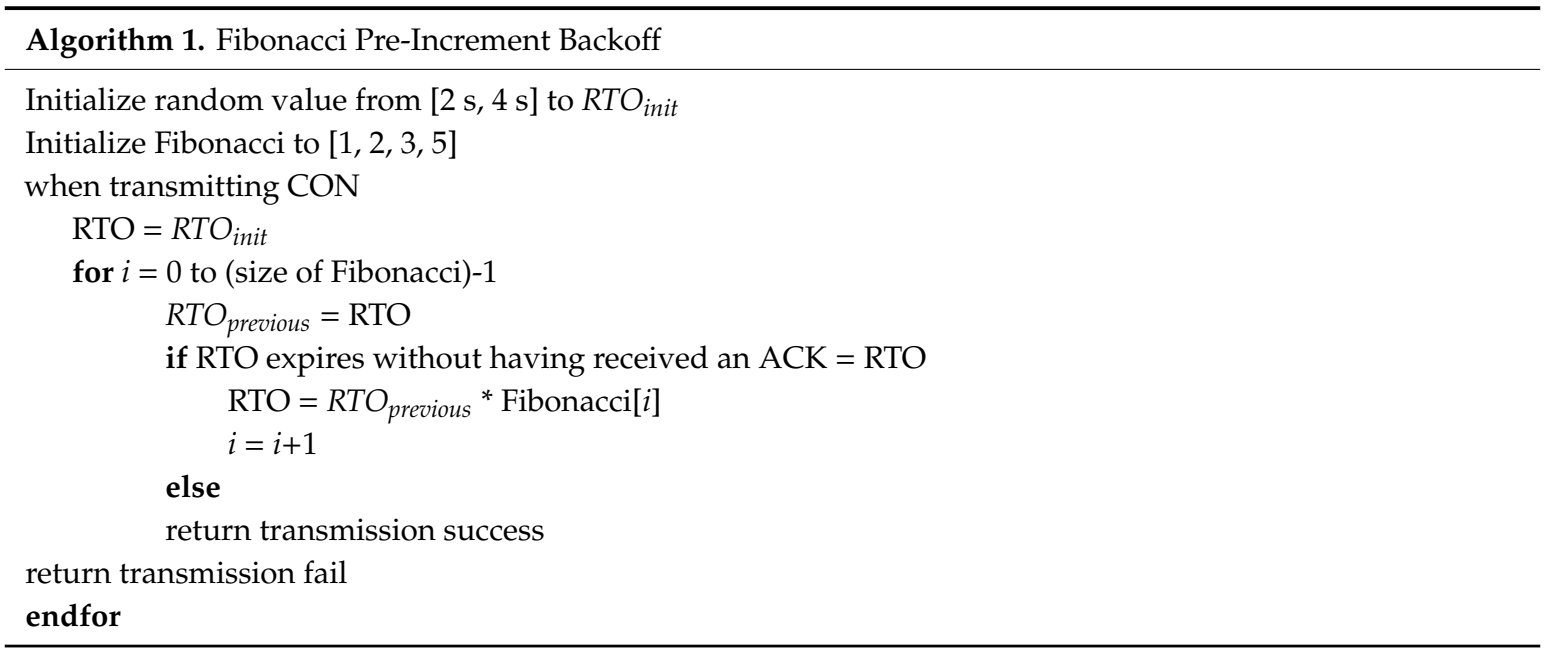




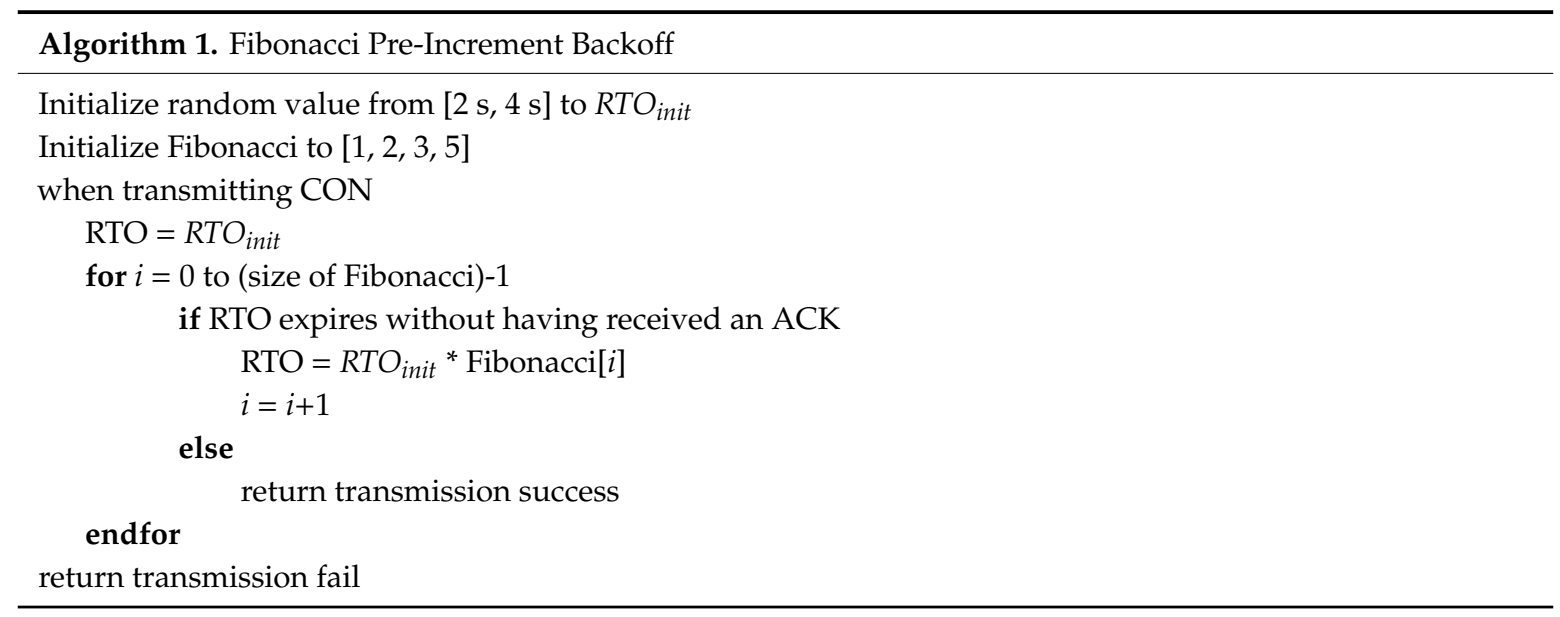

The changes do not affect the scientific results. The manuscript will be updated, and the original will remain online on the article webpage, with a reference to this Correction. The authors would like to apologize for any inconvenience caused to the readers by these changes.

\section{Reference}

1. Suwannapong, C.; Khunboa, C. Congestion Control in CoAP Observe Group Communication. Sensors 2019, 19, 3433. [CrossRef] [PubMed]

(C) 2019 by the authors. Licensee MDPI, Basel, Switzerland. This article is an open access article distributed under the terms and conditions of the Creative Commons Attribution (CC BY) license (http://creativecommons.org/licenses/by/4.0/). 